\title{
Numerical Simulations as Tool to Predict Chemical and Radiological Hazardous Diffusion in Case of Nonconventional Events
}

\author{
J.-F. Ciparisse, ${ }^{1}$ A. Malizia, ${ }^{1}$ L. A. Poggi, ${ }^{1}$ O. Cenciarelli, ${ }^{1}$ M. Gelfusa, ${ }^{1}$ M. C. Carestia, ${ }^{1}$ \\ D. Di Giovanni, ${ }^{1}$ S. Mancinelli, ${ }^{2}$ L. Palombi, ${ }^{2}$ C. Bellecci, ${ }^{1}$ and P. Gaudio ${ }^{1}$ \\ ${ }^{1}$ Department of Industrial Engineering, University of Rome "Tor Vergata", Via del Politecnico 1, 00133 Rome, Italy \\ ${ }^{2}$ Department of Biomedicine and Prevention, School of Medicine and Surgery, University of Rome "Tor Vergata", \\ Via Montpellier 1, 00133 Rome, Italy \\ Correspondence should be addressed to A. Malizia; malizia@ing.uniroma2.it
}

Received 29 September 2015; Revised 2 December 2015; Accepted 20 December 2015

Academic Editor: Javier Murillo

Copyright (C) 2016 J.-F. Ciparisse et al. This is an open access article distributed under the Creative Commons Attribution License, which permits unrestricted use, distribution, and reproduction in any medium, provided the original work is properly cited.

CFD (Computational Fluid Dynamics) simulations are widely used nowadays to predict the behaviour of fluids in pure research and in industrial applications. This approach makes it possible to get quantitatively meaningful results, often in good agreement with the experimental ones. The aim of this paper is to show how CFD calculations can help to understand the time evolution of two possible CBRNe (Chemical-Biological-Radiological-Nuclear-explosive) events: (1) hazardous dust mobilization due to the interaction between a jet of air and a metallic powder in case of a LOVA (Loss Of Vacuum Accidents) that is one of the possible accidents that can occur in experimental nuclear fusion plants; (2) toxic gas release in atmosphere. The scenario analysed in the paper has consequences similar to those expected in case of a release of dangerous substances (chemical or radioactive) in enclosed or open environment during nonconventional events (like accidents or man-made or natural disasters).

\section{Introduction}

Nowadays the perception of risks is completely changed if compared to that in the past. The geographical boundaries are thick such as the geopolitical ones. The social boundaries have totally disappeared leaving space to a world with different roles compared to the past. The globalization and the simplicity to access information from one side have improved technologies and quality of life but from the other side have created a higher facility to gather information to offend or create terror. The cases of the dispersion of toxic gas in the past and in the recent history [1-5], the DAESH progression in the Arabic Countries [6-10], the Ebola diffusion through the aerial transportation [11-17], and the radiological dispersion due to failures in fission or fusion devices [18-24] are all examples on how the new merge between the well-known risks and the new "dangerous ideas" has exponentially increased the uncertainties of the human health all around the world. The University of Rome
Tor Vergata, counting on the synergic work between the Faculty of Engineering and the Faculty of Medicine and Surgery, is facing these new problems with innovative working approaches voted to use the expertise developed in classic scientific disciplines in an unconventional way. In this paper the authors will demonstrate how the numerical simulations, in particular CFD techniques [25-39], can be a powerful tool to predict the consequences of particular accidents giving to the decision makers the chances to better manage the phases of accidents or terroristic events, reducing the risks associated. The authors will start to face the problem of toxic dust resuspension analysing first the problem itself that one of the possible causes of this phenomenon can be the LOVA and will show how these accidents can be approached with the numerical simulations. After that the authors will demonstrate how powerful are numerical simulations to simulate a toxic gas release as a consequence of a terroristic attack. The three cases analysed in this paper will be used to demonstrate that through the numerical simulations it is possible to 
predict accidental releases scenario (both radiological and chemical) in enclosed environment like a tank (that can be considered as a section of an industrial plant or like an office or a meeting room with an air conditioning plant) or in larger environment like chemical plant or a subway. The paper wants to demonstrate that every single accident, like the one studied in [40-52], can be faced not only from a technical point of view but also from an emergency management point of view. It is important to merge the different point of view and knowledge in order to use the numerical simulation as predicting tool for nonconventional event (like a dangerous release of a substances both man-made or caused by an accident or a natural event) in order to facilitate the phases of emergency management and restoration of normality.

The tool used to run the numerical simulation was COMSOL Multiphysics ${ }^{\circledR}$ version 5.1; the results have been analysed and are here discussed by the authors. For details about theory and settings, please refer to the COMSOL Multiphysics 5.1 User's Guide [53].

\section{Hazardous Dust Mobilization}

2.1. Nuclear Fusion Devices Security. Vacuum technologies are routinely used in many industrial and research applications. In some applications the macroscopic erosion of hazardous materials (radioactive, toxic, or explosive) and consequent accumulation of dust represent a risk for the workers and the population, for example, if the dust is mobilized during a loss of vacuum inside the vacuum vessel due to an accident in the system of a nuclear fusion power device. Improvement of accident management guidelines and mitigation measures of experimental nuclear fusion plants will significantly enhance the level of safety of the fusion facilities currently designed and the foreseen ITER and DEMO concepts [19].

Possible hazardous consequences from accidental dust mobilization prompted greater attention in the safety analyses of future high energy density fusion machines, like ITER or DEMO. One of the priorities that have been identified by the scientific community among the safety issues in this filed was the simulation of dust transport caused by a continuum phase ingress, water or air, into the vacuum vessel (VV) [54].

The Quantum Electronics and Plasma Physics (QEP) Research Group of the University of Rome Tor Vergata realized an experimental facility, STARDUST (Small Tank for Aerosol Removal and Dust) after modified in STARDUSTU (Upgrade) [55], in order to replicate experimental conditions comparable to particular thermofluid dynamic scenario expected in plants like ITER in case of LOVA (Loss Of Vacuum Accidents).

The experimental campaigns have been set at the beginning to collect data about the thermofluid dynamic behaviour in case of LOVA replications inside STARDUST and STARDUST-U. Together with these experimental campaigns the QEP research group carried out experiments to analyse the quantity of dust mobilized $[56,57]$ and determine the velocities direction and modules by the use of optical techniques $[58,59]$.
The numeric tool that will be developed will be a powerful instrument to predict the resuspension of dust (or particles) in enclosed environment. It will be possible to simulate several typologies of accidents like the ones expected in the nuclear fusion plants (like ITER). ITER has guidelines to determine how severe is an accident; these are on the Generic Site Safety Report [60].

The simulations, and the relative models, developed and presented in this section are essential tool to support the final aim of the work on safety and security of nuclear fusion plants that is finding a numerical multiphase model to predict the dust resuspension in case of accidents. For all simulations, an unstructured grid with wall refinement to capture the boundary layer was used. The convergence was considered to have been achieved when the maximum value of the residuals is below $1 e-4$ and show an asymptotic trend.

2.2. Numerical Simulations to Support Radiological Risks Prevision. The failure of a window or a breach in the metallic vessel of a subatmospheric tank is one of the major concerns about safety in future Tokamaks-based power plants. The understanding of the expansion into vacuum of the air surrounding the vessel is crucial in order to predict dust mobilization. Here, air is injected into a two-dimensional vessel, in which the initial pressure is $300 \mathrm{~Pa}$. As can be seen in Figure 1, a $1 \mathrm{~cm}$ diameter pipe allows the air to flow downwards into the vacuum chamber, and the specific mass flow rate of it varies over time according to this law:

$$
m=a \cdot(1-\exp (-b \cdot t))
$$

where $a=0.00056 \mathrm{~kg} / \mathrm{s}$ and $b=0.962 \mathrm{~s}^{-1}$.

The static temperature of the air is $293.15 \mathrm{~K}$ and the duration of the simulation is $10 \mathrm{~s}$. A fully compressible, turbulent flow was considered, and the governing equations are as follows.

Consider

Continuity Equation

$$
\frac{\partial \rho}{\partial t}+\vec{\nabla} \cdot(\rho \vec{V})=0
$$

Navier-Stokes Equation

$$
\begin{aligned}
& \rho \cdot\left(\frac{\partial \vec{V}}{\partial t}+(\vec{V} \vec{\nabla}) \vec{V}\right)=\vec{\nabla} \\
& \quad \cdot\left(\left(-p-\frac{2}{3}\left(\mu+\mu_{T}\right)(\vec{\nabla} \cdot \vec{V})-\frac{2}{3} \rho k\right) \cdot I\right. \\
& \left.\quad+\left(\mu+\mu_{T}\right)\left(\vec{\nabla} \vec{V}+(\vec{\nabla} \vec{V})^{T}\right)\right) .
\end{aligned}
$$



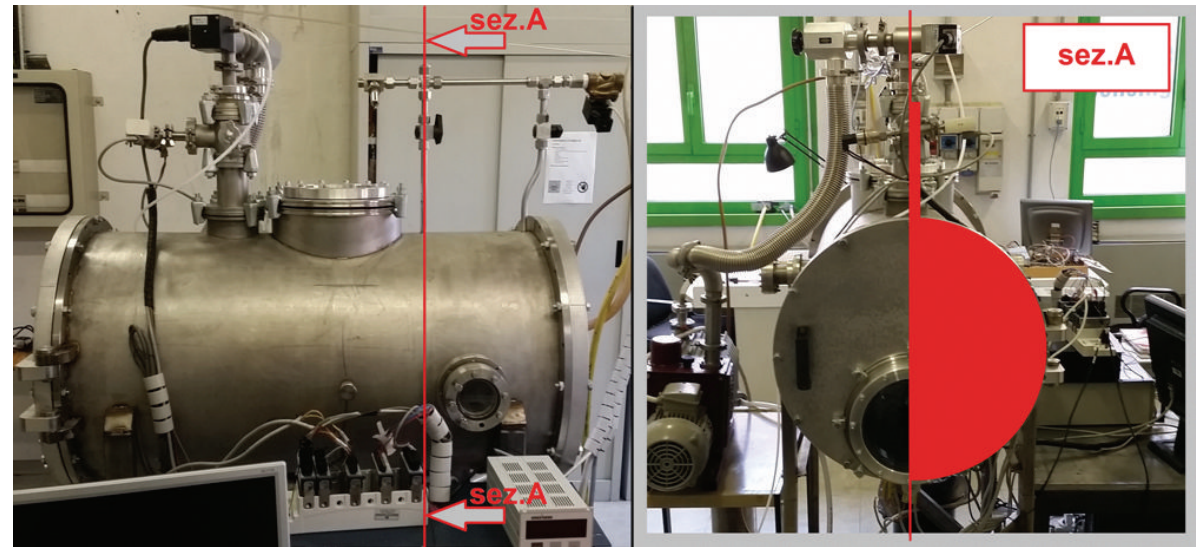

FIGURE 1: STARDUST facility picture showing the section ("sez.A") that is implemented in the numerical simulation software, as shown in Figures 2,3 , and 4 .

Energy Equation

$$
\begin{aligned}
\rho \cdot C_{p} & \cdot\left(\frac{\partial T}{\partial t}+(\vec{V} \cdot \vec{\nabla} T)\right) \\
= & \vec{\nabla} \cdot(\lambda \vec{\nabla} T)+\mu \\
& \cdot\left(\vec{\nabla} \vec{V}+(\vec{\nabla} \vec{V})^{T}-\frac{2}{3} \cdot(\vec{\nabla} \cdot \vec{V}) \cdot I\right): \vec{\nabla} \vec{V}+\vec{V} \\
& \cdot \vec{\nabla} p .
\end{aligned}
$$

Turbulent Kinetic Energy Conservation Equation

$$
\rho \cdot\left(\frac{\partial k}{\partial t}+(\vec{V} \vec{\nabla}) k\right)=\vec{\nabla} \cdot\left[\left(\mu+\frac{\mu_{T}}{\sigma_{k}}\right) \vec{\nabla} k\right]+P_{k}-\rho \epsilon .
$$

Turbulent Kinetic Energy Dissipation Rate Conservation Equation

$$
\begin{aligned}
\rho \cdot\left(\frac{\partial \epsilon}{\partial t}+(\vec{V} \vec{\nabla}) \varepsilon\right)= & \vec{\nabla} \cdot\left[\left(\mu+\frac{\mu_{T}}{\sigma_{\epsilon}}\right) \vec{\nabla} \epsilon\right]+C_{\epsilon 1} \frac{\epsilon}{k} P_{k} \\
& -C_{\epsilon 2} \rho \frac{\epsilon^{2}}{k} .
\end{aligned}
$$

\section{Turbulent Kinetic Energy Production Rate}

$$
\begin{aligned}
P_{k}= & \mu_{T} \cdot \vec{\nabla} \vec{V}:\left(\vec{\nabla} \vec{V}+(\vec{\nabla} \vec{V})^{T}-\frac{2}{3} \cdot(\vec{\nabla} \cdot \vec{V})^{2}\right)-\frac{2}{3} \rho k \\
& \cdot(\vec{\nabla} \cdot \vec{V}) .
\end{aligned}
$$

Turbulent Viscosity Equation

$$
\mu_{T}=\rho C_{\mu} \frac{k^{2}}{\epsilon} .
$$

\section{Perfect Gases State Equation}

$$
p=\rho R T
$$

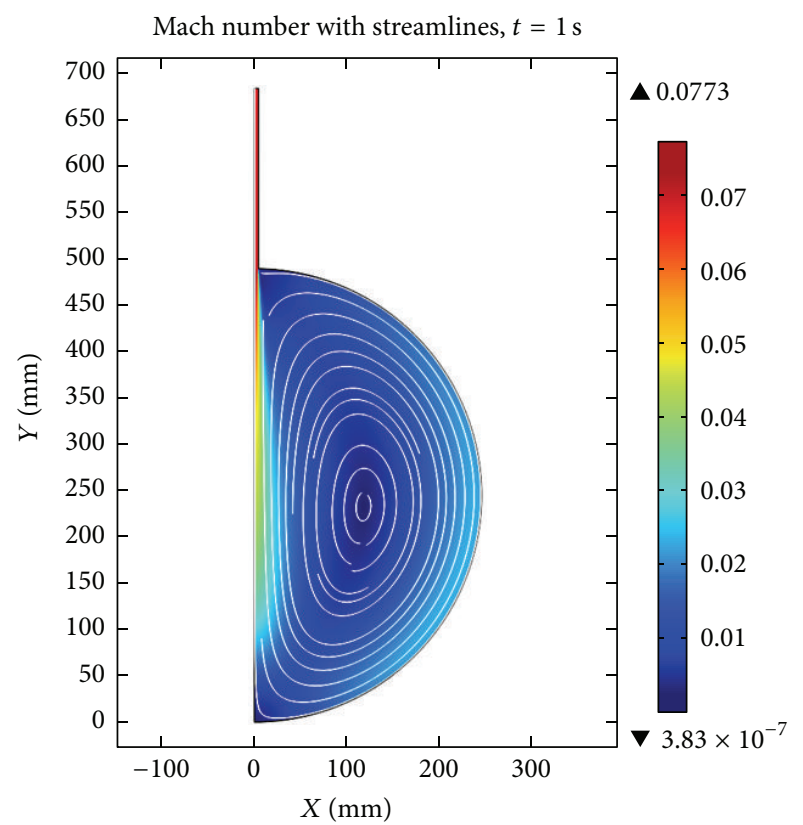

FIGURE 2: Mach number with streamlines after $1 \mathrm{~s}$.

In order to simulate this kind of flow, the High Mach Number Flow module of COMSOL was used. For further information, please see the CFD Module, High Mach Number Flow Interface, pages 282-304.

Figures 2, 3, and 4 show the Mach number fields with streamlines, respectively, after $1 \mathrm{~s}, 5 \mathrm{~s}$, and $10 \mathrm{~s}$ from the air inlet in the chamber.

As can be seen, a subsonic expansion of the gas occurs. The Mach number initially rises because of the mass flow rate increase as the valve opens. Then, while the vessel internal pressure rises along with the gas density, at a constant and fixed mass flow rate, the velocity decreases and therefore also the Mach number decreases. A great vortex, entrained by the jet of air, completely fills the vessel. This structure of the flow is manifestly very effective in mobilizing dust contained in the cavity. 


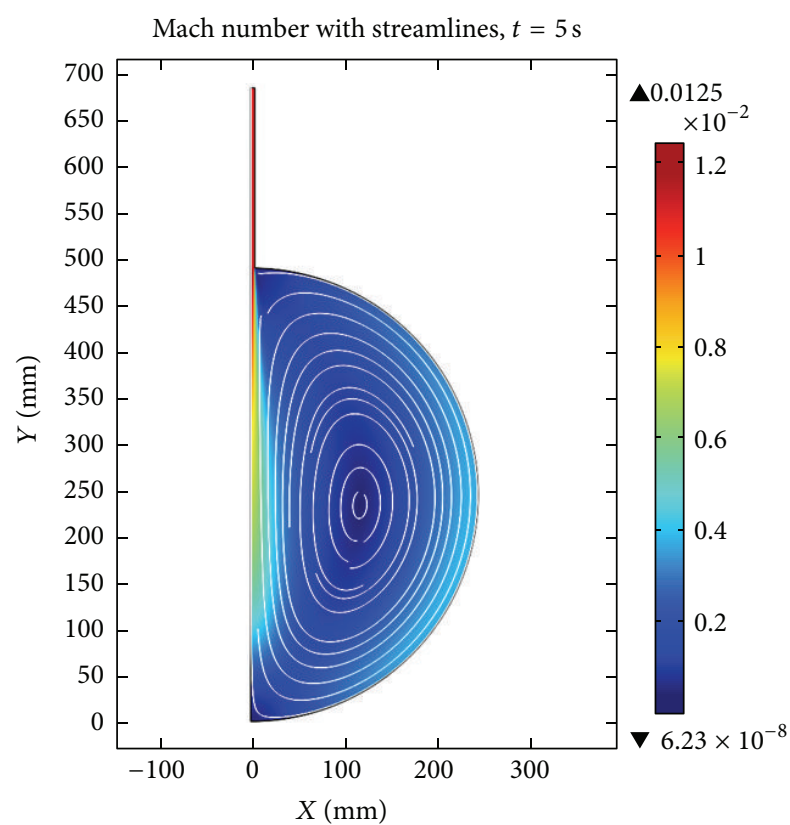

FIGURE 3: Mach number and streamlines after $5 \mathrm{~s}$.

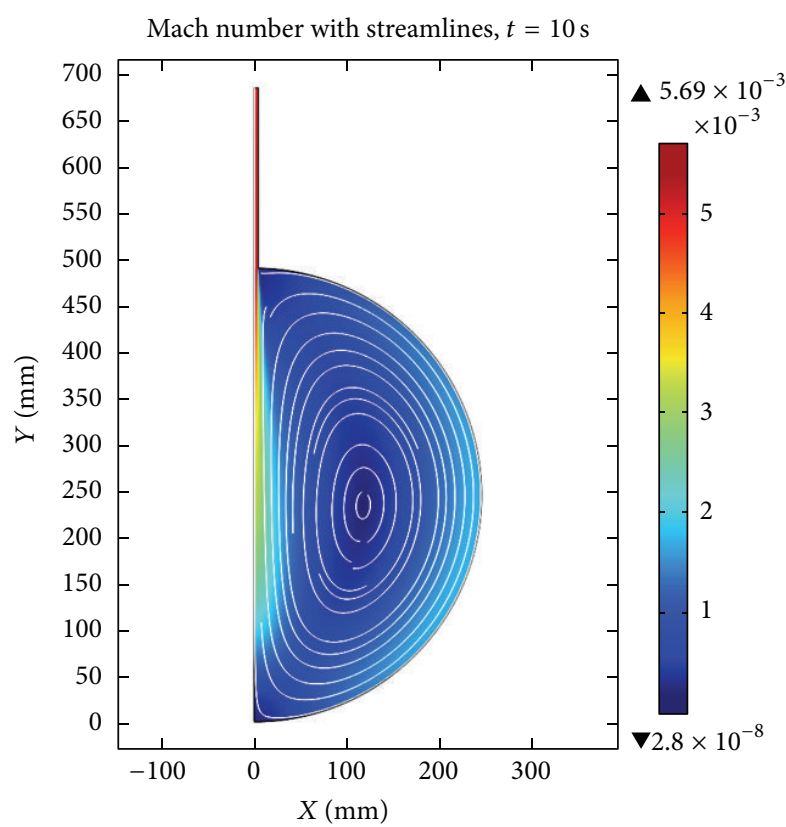

FIGURE 4: Mach number and streamlines after $10 \mathrm{~s}$.

Figures 5 and 6 present a comparison between numerical results obtained with the model presented and experimental results measured in STARDUST facility. The graph in Figure 5 shows the pressurization rate inside the chamber for the first 10 seconds. Please note that the experimental results are presented with error bars. The graph in Figure 6 shows the air velocity over time, calculated from the Ma number. The results are still not perfectly equal due to insufficiently fine grid and numerical viscosity effects but represent a first

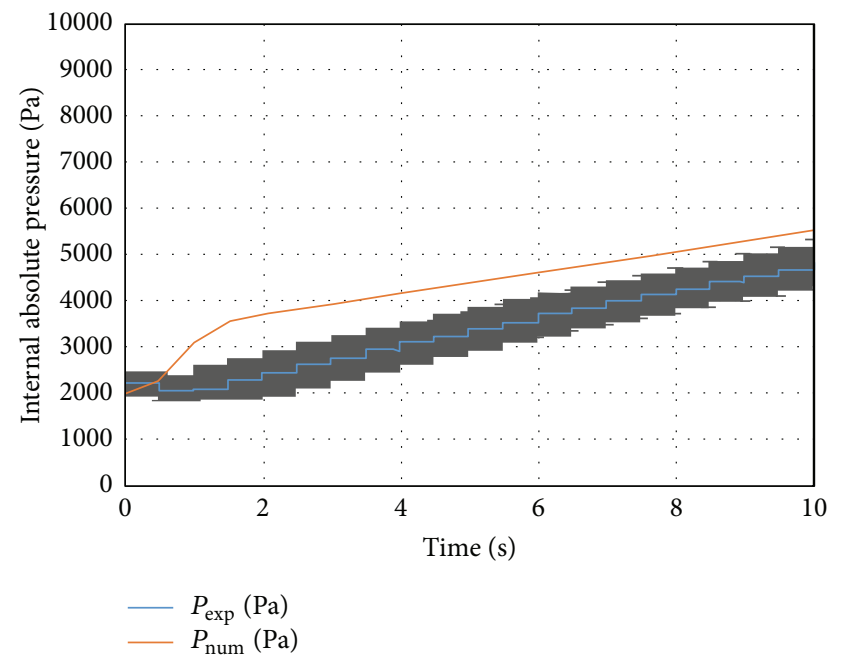

FIgURE 5: Pressurization of the chamber in the first $10 \mathrm{~s}$.

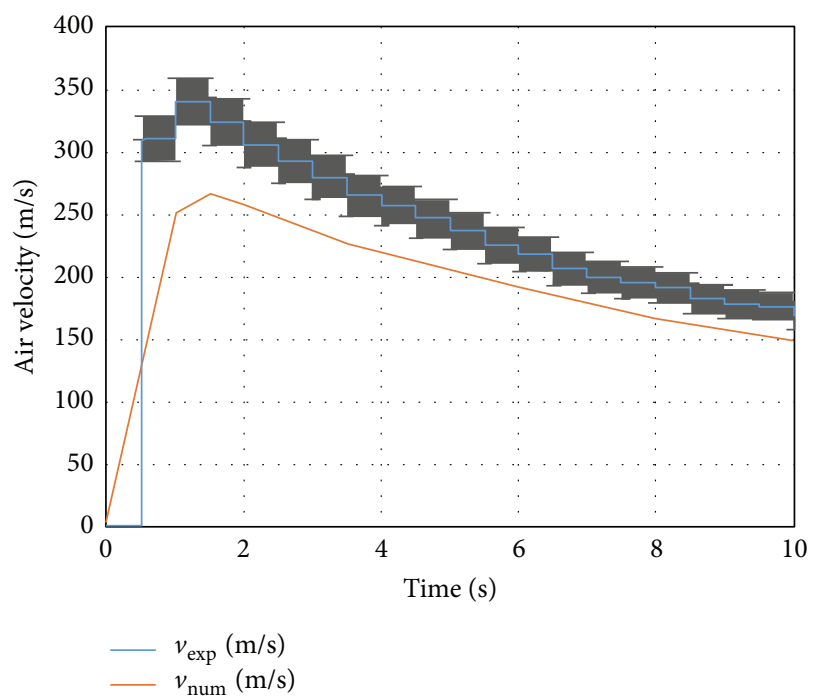

FIGURE 6: Local air velocity inside the STARDUST facility in the first $10 \mathrm{~s}$.

step towards the validation of the numerical model with the experimental data collected in STARDUST facility.

The second case study is about tungsten powder removal by an air jet flowing inside a cavity containing the dust. Figure 7 shows the physical two-dimensional domain (all lengths in $\mathrm{mm}$ ).

The air enters at $100 \mathrm{~m} / \mathrm{s}$ from the left upper side and exits from the upper right side that is imposed to be at atmospheric pressure. Initially, the air is at rest at $1 \mathrm{~atm}$ and a layer of tungsten powder, $3 \mathrm{~cm}$ thick, lies at the bottom of the cavity. The diameter of the solid particles is $0.4 \mu \mathrm{m}$ and the tungsten density is $19500 \mathrm{~kg} / \mathrm{m}^{3}$. The equations describing the behaviour of this two-phase flow are as follows.

Consider

Average Density Equation

$$
\rho=\rho_{c} \cdot\left(1-\varphi_{d}\right)+\rho_{d} \cdot \varphi_{d}
$$




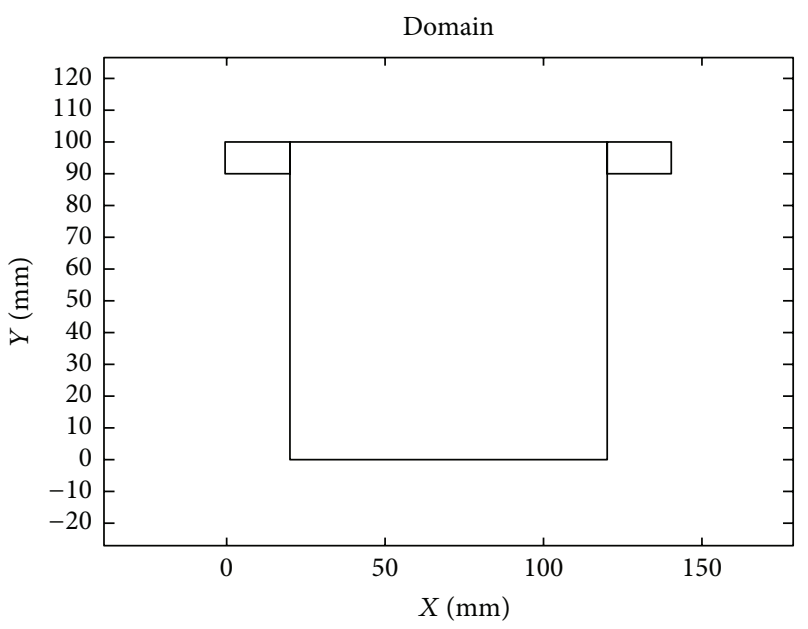

Figure 7: Physical domain.

Continuity Equation

$$
\frac{\partial \rho}{\partial t}+\vec{\nabla} \cdot(\rho \vec{V})=0
$$

Navier-Stokes Equation

$$
\begin{aligned}
& \rho \cdot\left(\frac{\partial \vec{V}}{\partial t}+(\vec{V} \vec{\nabla}) \vec{V}\right)=\vec{\nabla} \\
& \cdot\left(\left(-p-\frac{2}{3}\left(\mu+\mu_{T}\right)(\vec{\nabla} \cdot \vec{V})-\frac{2}{3} \rho k\right) \cdot I\right. \\
& \left.+\left(\mu+\mu_{T}\right)\left(\vec{\nabla} \vec{V}+(\vec{\nabla} \vec{V})^{T}\right)\right)-\vec{\nabla} \cdot\left[\rho \cdot c_{d} \cdot\left(1-c_{d}\right)\right. \\
& \cdot\left(\vec{u}_{\text {slip }}-\frac{D_{m d}}{1-c_{d}} \cdot \frac{\vec{\nabla} \varphi_{d}}{\varphi_{d}}\right)^{T} \\
& \left..\left(\vec{u}_{\text {slip }}-\frac{D_{m d}}{1-c_{d}} \cdot \frac{\vec{\nabla} \varphi_{d}}{\varphi_{d}}\right)^{T}\right]+\rho \cdot \vec{g} .
\end{aligned}
$$

Mass Balance between the Two Phases Equation

$$
\begin{aligned}
& \left(\rho_{c}-\rho_{d}\right) \\
& \cdot\left\{\vec{\nabla} \cdot\left[\varphi_{d} \cdot\left(1-c_{d}\right) \cdot \vec{u}_{\text {slip }}-D_{m d} \cdot \vec{\nabla} \varphi_{d}\right]-\vec{\nabla}\left(\varphi_{d} \cdot \vec{u}_{d}\right)\right\} \\
& +\rho_{c} \cdot \vec{\nabla} \cdot \vec{V}=0 .
\end{aligned}
$$

Momentum Balance between the Two Phases Equation

$$
\begin{aligned}
& \vec{u}_{d}=\vec{V}+\left(1-c_{d}\right) \cdot \vec{u}_{\text {slip }}-D_{m d} \cdot \frac{\vec{\nabla} \varphi_{d}}{\varphi_{d}}, \\
& c_{d}=\frac{\rho_{d} \cdot \varphi_{d}}{\rho},
\end{aligned}
$$

$$
\begin{aligned}
& D_{m d}=\frac{\mu_{T}}{\rho \cdot \sigma_{T}} \\
& 3 \cdot \frac{C_{d} \cdot \rho_{c}}{4 d_{d}} \cdot\left|\vec{u}_{\text {slip }}\right| \cdot \vec{u}_{\text {slip }} \\
& \quad=-\left(\rho-\rho_{d}\right) \cdot\left(-\frac{\partial \vec{V}}{\partial t}-\vec{V} \cdot(\vec{\nabla} \cdot \vec{V})+\vec{g}\right) .
\end{aligned}
$$

Effective Viscosity Equation

$$
\mu=\frac{\mu_{c}}{\left(1-\varphi_{d} / \varphi_{\max }\right)^{2.5 \cdot \varphi_{\max }}} .
$$

Drag Coefficient Calculation (Schiller-Naumann Model)

$$
C_{d}= \begin{cases}\frac{24}{\operatorname{Re}_{p}} \cdot\left(1+0.15 \cdot \mathrm{Re}_{p}^{0.687}\right), & \text { for } \mathrm{Re}_{p}<1000 \\ 0.44, & \text { for } \mathrm{Re}_{p}>1000\end{cases}
$$

Particle-Based Reynolds Number

$$
\operatorname{Re}_{p}=\frac{d_{d} \cdot \rho_{c} \cdot\left|\vec{u}_{\text {slip }}\right|}{\mu} .
$$

Energy Equation

$$
\begin{aligned}
\rho \cdot C_{p} & \cdot\left(\frac{\partial T}{\partial t}+(\vec{V} \cdot \vec{\nabla} T)\right) \\
= & \vec{\nabla} \cdot(k \vec{\nabla} T)+\mu \\
& \cdot\left(\vec{\nabla} \vec{V}+(\vec{\nabla} \vec{V})^{T}-\frac{2}{3} \cdot(\vec{\nabla} \cdot \vec{V}) \cdot I\right): \vec{\nabla} \vec{V}+\vec{V} \\
& \cdot \vec{\nabla} p .
\end{aligned}
$$

Turbulent Kinetic Energy Conservation Equation

$$
\rho \cdot\left(\frac{\partial k}{\partial t}+(\vec{V} \vec{\nabla}) k\right)=\vec{\nabla} \cdot\left[\left(\mu+\frac{\mu_{T}}{\sigma_{k}}\right) \vec{\nabla} k\right]+P_{k}-\rho \epsilon .
$$

Turbulent Kinetic Energy Dissipation Rate Conservation Equation

$$
\begin{aligned}
\rho \cdot\left(\frac{\partial \epsilon}{\partial t}+(\vec{V} \vec{\nabla}) \varepsilon\right)= & \vec{\nabla} \cdot\left[\left(\mu+\frac{\mu_{T}}{\sigma_{\epsilon}}\right) \vec{\nabla} \epsilon\right]+C_{\epsilon 1} \frac{\epsilon}{k} P_{k} \\
& -C_{\epsilon 2} \rho \frac{\epsilon^{2}}{k} .
\end{aligned}
$$

Turbulent Kinetic Energy Production Rate

$$
\begin{aligned}
P_{k}= & \mu_{T} \cdot \vec{\nabla} \vec{V}:\left(\vec{\nabla} \vec{V}+(\vec{\nabla} \vec{V})^{T}-\frac{2}{3} \cdot(\vec{\nabla} \cdot \vec{V})^{2}\right)-\frac{2}{3} \rho k \\
& \cdot(\vec{\nabla} \cdot \vec{V}) .
\end{aligned}
$$




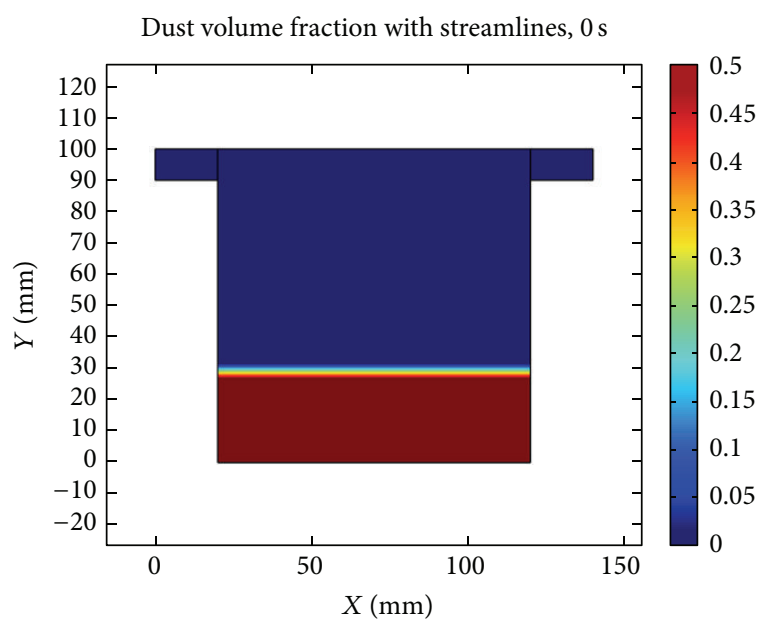

FIGURE 8: Dust initial volume fraction.

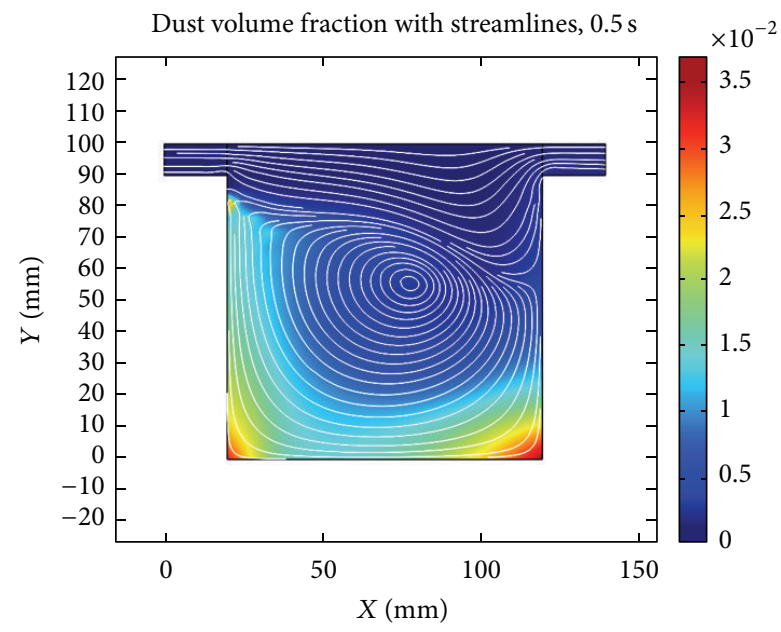

FIGURE 9: Dust volume fraction with streamlines after $0.5 \mathrm{~s}$.

Turbulent Viscosity Calculation

$$
\mu_{T}=\rho C_{\mu} \frac{k^{2}}{\epsilon} .
$$

Perfect Gases State Equation

$$
p=\rho R T
$$

The full model takes into account the drift (or slip) speed between the air and the particle, and the Schiller-Naumann drag model was used. To simulate this flow, the multiphase module using the turbulent Euler/Euler transport model was used. For further details, see the CFD Module, Multiphase Flow, the Euler/Euler Model Interface, pages 360-371.

Figures 8,9 , and 10 show the dust volume fraction and the streamlines at $0 \mathrm{~s}, 0.5 \mathrm{~s}$, and $1 \mathrm{~s}$.

As can be seen, the vortex that forms in this driven cavity rapidly entrains the dust, so its fallout and the contamination of the surroundings of the release point of the powder have to be expected. The high mobilization speed is due to

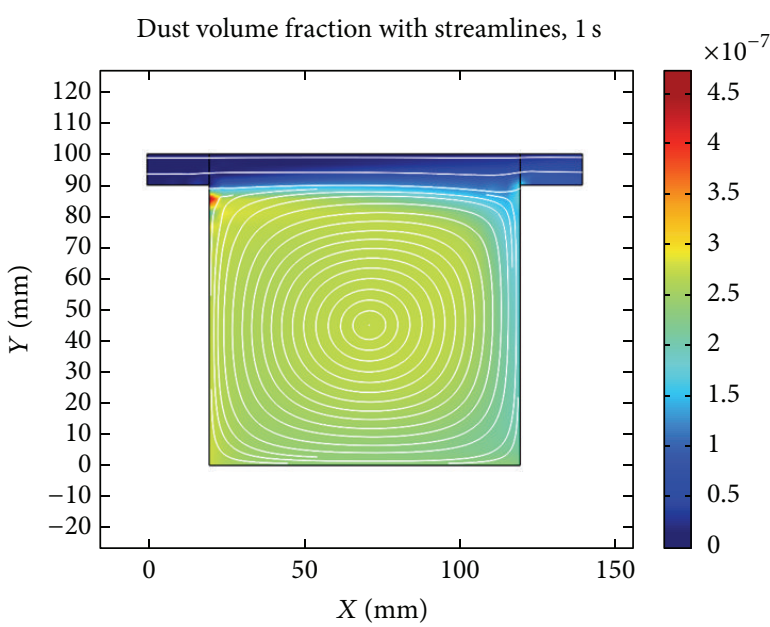

FIGURE 10: Dust volume fraction with streamlines after $1 \mathrm{~s}$.

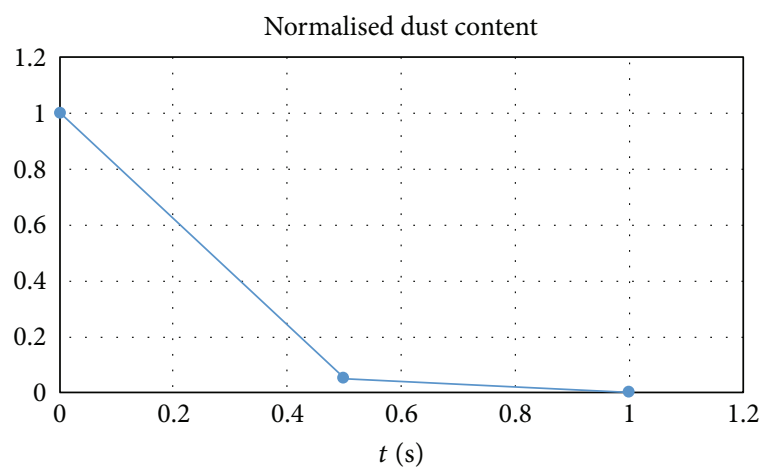

Figure 11: Normalised dust content versus time.

the velocity of the inlet air jet. The order of magnitude of the speed $(100 \mathrm{~m} / \mathrm{s})$ is common when dust is blown by an air jet during an accident/terroristic attack. Figure 11 shows the evolution in time of the mass content of dust in the cavity, normalised with respect to its initial value.

The mobilization speed has been confirmed by experiments carried out in the STARDUST-U facility of the Industrial Engineering Department of the University of Rome Tor Vergata. This kind of accident can occur in Tokamaks, when a LOVA happens or when hazardous dust is accidentally or voluntarily exposed to the wind. It is clear from Figure 11 that almost the total amount of dust is resuspended in the first second after the air inlet in accordance with the peak of air velocities measured (see $[19,54,57])$ and the dust mobilized during the experimental campaigns (see $[56,58,59]$ ).

Once the multiphase model has been developed and validated through a comparison with the experimental data, changing the boundary conditions (geometry, temperatures, flow rates, etc.), it can be used to simulate the release or mobilization of other dangerous compounds (like chemical agents or biological agents). 


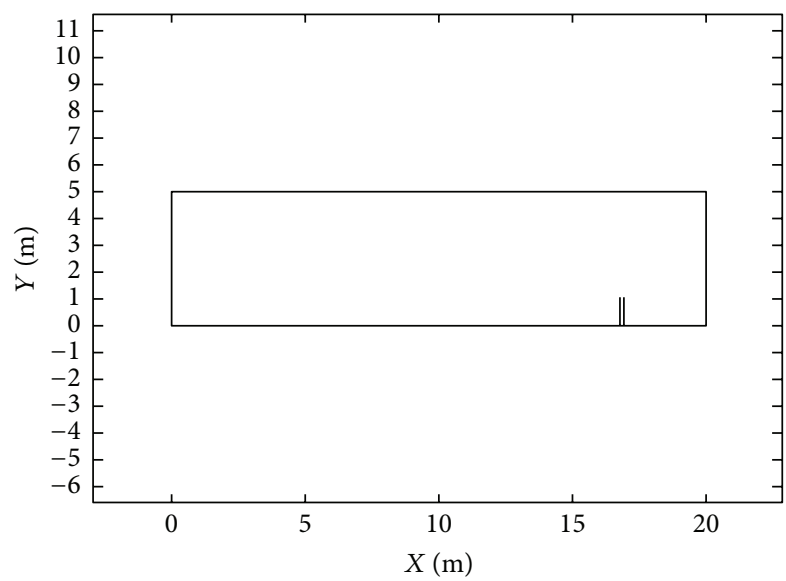

FIgUre 12: Physical domain.

\section{Toxic Gas Release}

The diffusion of harmful gases in the atmosphere is the result of several causes: terroristic attack, failure of a vessel in a chemical plant, gaseous exhaust of a factory, and many others [1-5]. Here, a release of chlorine was considered as a case study. Referring to Figure 10, chlorine flows upwards in a vertical pipe, blown from the right by the wind. The wind speed is $5 \mathrm{~m} / \mathrm{s}$ and the chlorine pressure at the base of the pipe is $1.5 \mathrm{~atm}$. On the upper and left edges of the domain, atmospheric pressure was imposed. The simulation time is $10 \mathrm{~s}$. Initially, the domain is filled with air; then chlorine starts to flow and to be released in the atmosphere.

The domain is two-dimensional, as shown in Figure 12, and all dimensions are expressed in meters.

The gas is considered as a mixture of air and chlorine. The simulation is unsteady and was carried out with COMSOL Multiphysics. The flow is turbulent, compressible, and nonisothermal. The general equations describing the behaviour of the flow are as follows.

Consider

\section{Continuity Equation}

$$
\frac{\partial \rho}{\partial t}+\vec{\nabla} \cdot(\rho \vec{V})=0
$$

Navier-Stokes Equation

$$
\begin{aligned}
& \rho \cdot\left(\frac{\partial \vec{V}}{\partial t}+(\vec{V} \vec{\nabla}) \vec{V}\right)=\vec{\nabla} \\
& \quad \cdot\left(\left(-p-\frac{2}{3}\left(\mu+\mu_{T}\right)(\vec{\nabla} \cdot \vec{V})-\frac{2}{3} \rho k\right) \cdot I\right. \\
& \left.\quad+\left(\mu+\mu_{T}\right)\left(\vec{\nabla} \vec{V}+(\vec{\nabla} \vec{V})^{T}\right)\right) .
\end{aligned}
$$

Energy Equation

$$
\begin{aligned}
\rho \cdot C_{p} & \cdot\left(\frac{\partial T}{\partial t}+(\vec{V} \cdot \vec{\nabla} T)\right) \\
= & \vec{\nabla} \cdot(k \vec{\nabla} T)+\mu \\
& \cdot\left(\vec{\nabla} \vec{V}+(\vec{\nabla} \vec{V})^{T}-\frac{2}{3} \cdot(\vec{\nabla} \cdot \vec{V}) \cdot I\right): \vec{\nabla} \vec{V}+\vec{V} \\
& \cdot \vec{\nabla} p .
\end{aligned}
$$

\section{Turbulent Kinetic Energy Conservation Equation}

$$
\rho \cdot\left(\frac{\partial k}{\partial t}+(\vec{V} \vec{\nabla}) k\right)=\vec{\nabla} \cdot\left[\left(\mu+\frac{\mu_{T}}{\sigma_{k}}\right) \vec{\nabla} k\right]+P_{k}-\rho \epsilon .
$$

Turbulent Kinetic Energy Dissipation Rate

Conservation Equation

$$
\begin{aligned}
\rho \cdot\left(\frac{\partial \epsilon}{\partial t}+(\vec{V} \vec{\nabla}) \varepsilon\right)= & \vec{\nabla} \cdot\left[\left(\mu+\frac{\mu_{T}}{\sigma_{\epsilon}}\right) \vec{\nabla} \epsilon\right]+C_{\epsilon 1} \frac{\epsilon}{k} P_{k} \\
& -C_{\epsilon 2} \rho \frac{\epsilon^{2}}{k} .
\end{aligned}
$$

Turbulent Kinetic Energy Production Rate

$$
\begin{aligned}
P_{k}= & \mu_{T} \cdot \vec{\nabla} \vec{V}:\left(\vec{\nabla} \vec{V}+(\vec{\nabla} \vec{V})^{T}-\frac{2}{3} \cdot(\vec{\nabla} \cdot \vec{V})^{2}\right)-\frac{2}{3} \rho k \\
& \cdot(\vec{\nabla} \cdot \vec{V}) .
\end{aligned}
$$

Turbulent Viscosity Equation

$$
\mu_{T}=\rho C_{\mu} \frac{k^{2}}{\epsilon}
$$

Perfect Gases State Equation

$$
p=\rho R T
$$

Species Conservation Equation

$$
\vec{\nabla} \cdot \vec{j}_{i}+\rho \cdot\left(\frac{\partial \omega_{i}}{\partial t}+(\vec{V} \cdot \vec{\nabla}) \omega_{i}\right)=R_{i}
$$

ith Species Diffusive Flux

$$
\begin{aligned}
\vec{j}_{i}= & -\left(\rho\left(D_{i}^{m}+\frac{\nu_{T}}{\mathrm{Sc}_{T}}\right) \cdot \vec{\nabla} \omega_{i}+\rho \omega_{i} D_{i}^{m} \cdot \frac{\vec{\nabla} M_{n}}{M_{n}}+D_{i}^{T}\right. \\
& \left.\cdot \frac{\vec{\nabla} T}{T}\right) .
\end{aligned}
$$




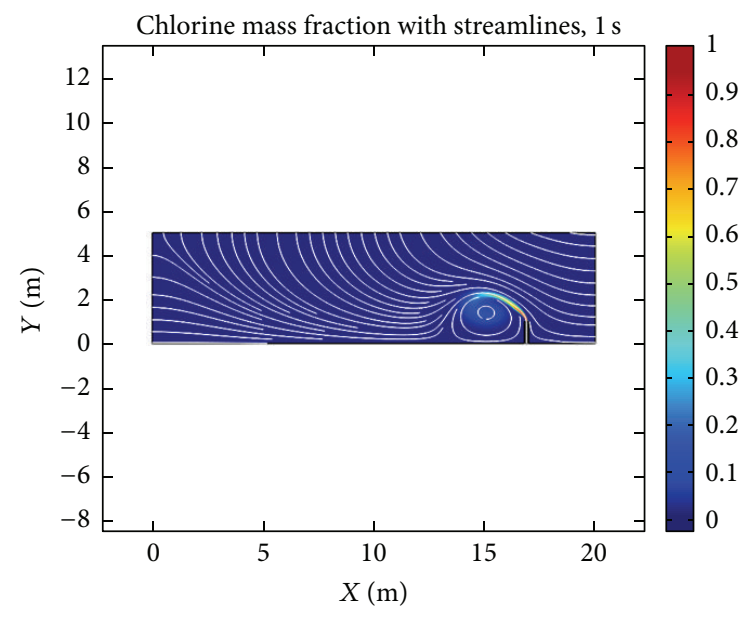

FIGURE 13: Chlorine mass fraction with streamlines after $1 \mathrm{~s}$.

ith Species Mass Molecular Diffusion Coefficient

$$
D_{i}^{m}=\frac{1-\omega_{i}}{\sum_{k \neq i}\left(x_{k} / D_{i k}\right)} .
$$

Mean Molar Mass

$$
M_{n}=\left(\sum_{i} \frac{\omega_{i}}{M_{i}}\right)^{-1},
$$

where $\omega_{i}$ is the mass fraction of the $i$ th species, $x_{i}$ is its molar fraction, $\mathrm{Sc}_{T}$ is the Schmidt turbulent number, and $D_{i k}$ is the binary diffusion coefficient between $i$ th and $k$ th species. This simulation was performed by using the Concentrated Species Interface and the Single-Phase Flow Interface. For further details, see the CFD Module, Single-Phase Flow Interface module, Theory for Turbulent Flow Interfaces, pages 136172, and the Chemical Reactions Module, Chemical Species Transport Interfaces, and Transport of Concentrated Species, pages 196-211.

Figures 13, 14, and 15 show the chlorine mass fraction with streamlines at $1 \mathrm{~s}, 5 \mathrm{~s}$, and $10 \mathrm{~s}$.

As can be seen, an unsteady vortices system forms behind the pipe and the chlorine plume, and this gas is rapidly mixed in the air by the eddies, so the whole zone behind the release point of the gas is contaminated.

\section{Conclusions}

Expansion into vacuum, dust mobilization, and gaseous mixing were investigated by means of numerical simulations. It was found that this approach is well suited for studying this kind of safety problems and makes it possible to predict the transient evolution of the phenomena involved in CBRNe events. A further development of this technique will be the study of accidents/terroristic attacks occurring in threedimensional domains under realistic conditions. It is in fact well known that turbulent flows are intrinsically unsteady and

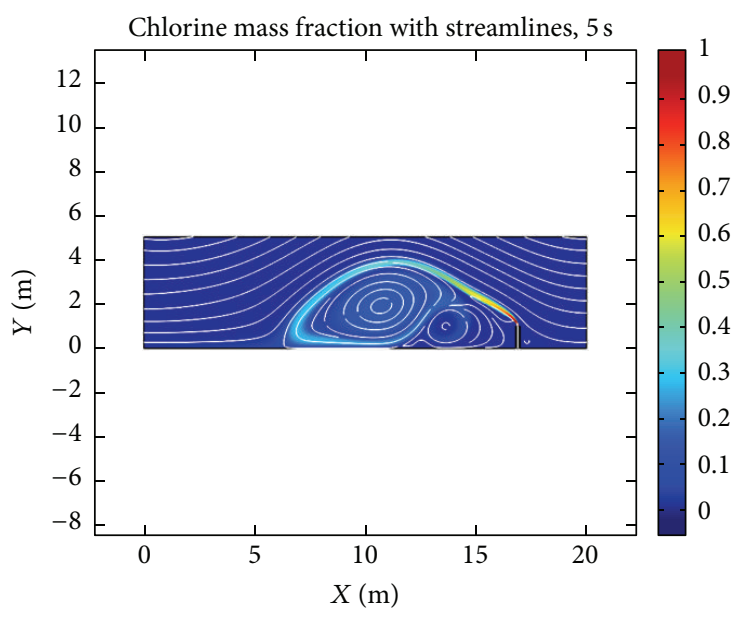

FIGURE 14: Chlorine mass fraction with streamlines after $5 \mathrm{~s}$.

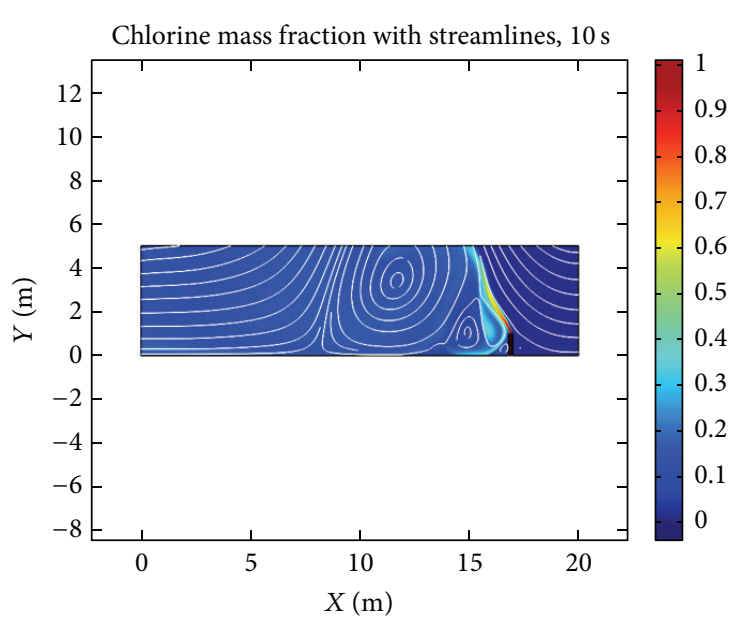

FIGURE 15: Chlorine mass fraction with streamlines after $10 \mathrm{s.}$

three-dimensional, rather than bidimensional. So, as turbulence plays a crucial role in the flow behaviour, especially with respect to pollutants transport, a more realistic $3 \mathrm{D}$ modelling of the flow is to be preferred. It is also known that a $3 \mathrm{D}$ domain allows movements in the third dimension which are not possible in $2 \mathrm{D}$. In other words, a $3 \mathrm{D}$ simulation fits better the real flow than a $2 \mathrm{D}$ one. The drawback of this approach is the greater requirement of RAM and the higher number of processors.

Building synthetic models on the basis of numerical results obtained for each class of problem under several conditions (speed of wind, mass flow rate of the pollutants, and so on) is intended in the future. The approach is the same as the one used by experimental researchers to determine empirical correlations. In such a way, the models can be used by the in-field operators just by inserting as inputs the above-mentioned conditions and will give as an output the pollutants concentration, which is the required data to evaluate the safety risks. 


\section{Nomenclature}

\begin{tabular}{|c|c|}
\hline$\rho:$ & Density \\
\hline$\vec{V}:$ & Velocity vector \\
\hline$p:$ & Pressure \\
\hline$\lambda:$ & Thermal conductivity \\
\hline$C_{p}:$ & Constant pressure specific heat \\
\hline$T:$ & Temperature \\
\hline$R:$ & Gas constant \\
\hline$\mu:$ & Molecular viscosity \\
\hline$\mu_{T}:$ & Turbulent viscosity \\
\hline$k:$ & Turbulent kinetic energy \\
\hline$\varepsilon:$ & $\begin{array}{l}\text { Turbulent kinetic energy dissipation } \\
\text { rate }\end{array}$ \\
\hline$P_{k}:$ & $\begin{array}{l}\text { Turbulent kinetic energy production } \\
\text { term }\end{array}$ \\
\hline$C_{\epsilon 1}, C_{\epsilon 2}$, and $C_{\mu}$ : & Turbulence model constants \\
\hline$\vec{j}_{i}:$ & $i$ th species diffusive flux \\
\hline$\omega_{i}:$ & $i$ th species mass fraction \\
\hline$x_{i}:$ & $i$ th species molar fraction \\
\hline$M_{i}:$ & ith species molar mass \\
\hline$M_{n}:$ & Mean molar mass \\
\hline$R_{i}:$ & ith species source term \\
\hline$D_{i}^{m}:$ & $\begin{array}{l}\text { ith species mass molecular diffusion } \\
\text { coefficient }\end{array}$ \\
\hline$D_{i k}:$ & $\begin{array}{l}\text { Binary diffusion coefficient between } i \text { th } \\
\text { and } k \text { th species }\end{array}$ \\
\hline $\mathrm{Sc}_{T}:$ & Turbulent Schmidt number \\
\hline$\nu_{T}:$ & Turbulent kinematic viscosity \\
\hline$\varphi_{d}:$ & Dispersed particles volume fraction \\
\hline$c_{d}:$ & Dispersed phase mass fraction \\
\hline$\rho_{c}:$ & Continuous phase density \\
\hline$\rho_{d}:$ & Dispersed phase density \\
\hline$d_{d}:$ & Dispersed phase particles diameter \\
\hline$\vec{u}_{c}:$ & Continuous phase velocity vector \\
\hline$\vec{u}_{d}:$ & Dispersed phase velocity vector \\
\hline$\vec{u}_{\text {slip }}:$ & Slip velocity \\
\hline$\vec{g}:$ & Gravity acceleration vector \\
\hline$\varphi_{\max }:$ & Maximum particles volume fraction \\
\hline$C_{d}:$ & Particles drag coefficient \\
\hline $\operatorname{Re}_{p}:$ & Particle-based Reynolds number. \\
\hline
\end{tabular}

\section{Conflict of Interests}

The authors declare that there is no conflict of interests regarding the publication of this paper.

\section{References}

[1] T. Okumura, K. Suzuki, A. Fukuda et al., "The Tokyo subway sarin attack: disaster management, part 1: community emergency response," Academic Emergency Medicine, vol. 5, no. 6, pp. 613-617, 1998.

[2] S. Varney, J. M. Hirshon, P. Dischinger, and C. Mackenzie, "Extending injury prevention methodology to chemical terrorism preparedness: the Haddon Matrix and sarin," American Journal of Disaster Medicine, vol. 1, no. 1, pp. 18-27, 2006.

[3] B. C. Singer, A. T. Hodgson, H. Destaillats, T. Hotchi, K. L. Revzan, and R. G. Sextro, "Indoor sorption of surrogates for sarin and related nerve agents," Environmental Science and Technology, vol. 39, no. 9, pp. 3203-3214, 2005.

[4] M. H. Wood, "The Seveso II experience in the application of generic substance criteria to identify major hazard sites," Journal of Hazardous Materials, vol. 171, no. 1-3, pp. 16-28, 2009.

[5] M. Connelly, "The ypres league and the commemoration of the ypres salient, 1914-1940," War in History, vol. 16, no. 1, pp. 51-76, 2009.

[6] J. Hansen-Lewis and J. N. Shapiro, "Understanding the daesh economy," Perspective on Terrorism, vol. 9, no. 4, 2015.

[7] J. Fromson and S. Simon, "ISIS: the dubious paradise of apocalypse now," Survival, vol. 57, no. 3, pp. 7-56, 2015.

[8] S. Akbarzadeh, "Iran and Daesh: the case of a reluctant Shia power," Middle East Policy, vol. 22, no. 3, pp. 44-54, 2015.

[9] D. Esfandiary and A. Tabatabai, "Iran's ISIS policy," International Affairs, vol. 91, no. 1, pp. 1-15, 2015.

[10] L. Tomé, “The 'Islamic State': trajectory and reach a year after its self-proclamation as a 'Caliphate," Janus.net, vol. 6, no. 1, pp. 116-139, 2015.

[11] O. Cenciarelli, S. Pietropaoli, A. Malizia et al., "Ebola virus disease 2013-2014 outbreak in West Africa: an analysis of the epidemic spread and response," International Journal of Microbiology, vol. 2015, Article ID 769121, 12 pages, 2015.

[12] O. Cenciarelli, S. Pietropaoli, L. Frusteri et al., "Biological emergency management: the case of Ebola 2014 and the air transportation involvement," Journal of Microbial and Biochemical Technology, vol. 6, no. 5, pp. 247-253, 2014.

[13] O. Cenciarelli, V. Gabbarinic, S. Pietropaoli et al., "Viral bioterrorism: learning the lesson of Ebola virus in West Africa 20132015," Virus Research, vol. 210, pp. 318-326, 2015.

[14] K. J. Olival, A. Islam, M. Yu et al., "Ebola virus antibodies in fruit bats, bangladesh," Emerging Infectious Diseases, vol. 19, no. 2, pp. 270-273, 2013.

[15] R. R. Lash, N. A. Brunsell, and A. T. Peterson, "Spatiotemporal environmental triggers of Ebola and Marburg virus transmission," Geocarto International, vol. 23, no. 6, pp. 451-466, 2008.

[16] G. Rainisch, M. Shankar, M. Wellman, T. Merlin, and M. I. Meltzer, "Regional spread of Ebola virus, west Africa, 2014," Emerging Infectious Diseases, vol. 21, no. 3, pp. 444-447, 2015.

[17] P. P. Gupta, D. I. Jasnaik, and P. K. Panda, "Ebola virus: bioterrorism for humans," Asian Pacific Journal of Tropical Disease, vol. 5, supplement 1, pp. S1-S6, 2015.

[18] I. Cacciotti, P. C. Aspetti, O. Cenciarelli et al., "Simulation of Caesium-137 (137CS) local diffusion as a consequence of the Chernobyl accident using HOTSPOT," Defence SøT Technical Bulletin, vol. 7, no. 1, pp. 18-26, 2014.

[19] A. Malizia, I. Lupelli, M. Richetta, M. Gelfusa, C. Bellecci, and P. Gaudio, "Safety analysis in large volume vacuum systems like tokamak: experiments and numerical simulation to analyze vacuum ruptures consequences," Advances in Materials Science and Engineering, vol. 2014, Article ID 201831, 29 pages, 2014.

[20] R. Gallo, P. de Angelis, A. Malizia et al., "Development of a georeferencing software for radiological diffusion in order to improve the safety and security of first responders," Defence $S$ \& T Technical Bulletin, vol. 6, no. 1, pp. 21-32, 2013.

[21] R. J. M. Konings, T. Wiss, and O. Beneš, "Predicting material release during a nuclear reactor accident," Nature Materials, vol. 14, no. 3, pp. 247-252, 2015.

[22] G. Espinosa-Paredes, R. Camargo-Camargo, and A. NuñezCarrera, "Severe accident simulation of the laguna verde nuclear 
power plant," Science and Technology of Nuclear Installations, vol. 2012, Article ID 209420, 11 pages, 2012.

[23] A. Malins, H. Kurikami, S. Nakama et al., "Evaluation of ambient dose equivalent rates influenced by vertical and horizontal distribution of radioactive cesium in soil in Fukushima Prefecture," Journal of Environmental Radioactivity, vol. 151, article 4919, pp. 38-49, 2016.

[24] M. A. B. Alvarenga and P. F. F. e Melo, "Including severe accidents in the design basis of nuclear power plants: an organizational factors perspective after the Fukushima accident," Annals of Nuclear Energy, vol. 79, pp. 68-77, 2015.

[25] I. Lupelli, A. Malizia, M. Richetta et al., "Simulations and experiments to reach numerical multiphase informations for security analysis on large volume vacuum systems like tokamaks," Journal of Fusion Energy, vol. 34, no. 5, pp. 959-978, 2015.

[26] A. Davari, S. M. Mirvakili, and E. Abedi, "Three-dimensional analysis of flow blockage accident in Tehran MTR research reactor core using CFD," Progress in Nuclear Energy, vol. 85, pp. 605-612, 2015.

[27] J. Burman and L. Jonsson, "Issues when linking computational fluid dynamics for urban modeling to toxic load models: the need for further research," Atmospheric Environment, vol. 104, pp. 112-124, 2015.

[28] P. Middha, O. R. Hansen, J. Grune, and A. Kotchourko, "CFD calculations of gas leak dispersion and subsequent gas explosions: validation against ignited impinging hydrogen jet experiments," Journal of Hazardous Materials, vol. 179, no. 1-3, pp. 84-94, 2010.

[29] I. Lupelli, P. Gaudio, M. Gelfusa, A. Malizia, I. Belluzzo, and M. Richetta, "Numerical study of air jet flow field during a loss of vacuum," Fusion Engineering and Design, vol. 89, no. 9-10, pp. 2048-2052, 2014.

[30] N. Agrawal and S. K. Das, "Numerical studies on hydrogen distribution in enclosures in the presence of condensing steam," Journal of Heat Transfer, vol. 137, no. 12, Article ID 121008, 2015.

[31] B. Wang, B. Chen, and J. Zhao, "The real-time estimation of hazardous gas dispersion by the integration of gas detectors, neural network and gas dispersion models," Journal of Hazardous Materials, vol. 300, pp. 433-442, 2015.

[32] J. G. Bartzis, G. C. Efthimiou, and S. Andronopoulos, "Modelling short term individual exposure from airborne hazardous releases in urban environments," Journal of Hazardous Materials, vol. 300, pp. 182-188, 2015.

[33] A. Galeev, A. Salin, and S. Ponikarov, "Numerical simulation of evaporation of volatile liquids," Journal of Loss Prevention in the Process Industries, vol. 38, pp. 39-49, 2015.

[34] C. Liu, C. Ng, and C. C. Wong, "A theory of ventilation estimate over hypothetical urban areas," Journal of Hazardous Materials, vol. 296, pp. 9-16, 2015.

[35] X. Liu, A. Godbole, C. Lu, G. Michal, and P. Venton, "Optimisation of dispersion parameters of Gaussian plume model for $\mathrm{CO}_{2}$ dispersion," Environmental Science and Pollution Research, vol. 22, no. 22, pp. 18288-18299, 2015.

[36] K. B. Mishra, "CFD model for large hazardous dense cloud spread predictions, with particular reference to Bhopal disaster," Atmospheric Environment, vol. 117, pp. 74-91, 2015.

[37] M. Parvini and E. Gharagouzlou, "Gas leakage consequence modeling for buried gas pipelines," Journal of Loss Prevention in the Process Industries, vol. 37, pp. 110-118, 2015.

[38] P. V. Nielsen, "Fifty years of CFD for room air distribution," Building and Environment, vol. 91, pp. 78-90, 2015.
[39] S. Ben Hamza, S. Habli, N. Mahjoub Saïd, H. Bournot, and G. Le Palec, "Simulation of pollutant dispersion of a free surface flow in coastal water," Ocean Engineering, vol. 108, pp. 81-97, 2015.

[40] F. Pirelli, O. Cenciarelli, V. Gabbarini et al., "Maritime security: applications and perspectives to combat chemical, radiological and explosive threats," Defence S \& T Technical Bulletin, vol. 7, no. 2, pp. 90-98, 2014.

[41] Centers for Disease Control and Prevention, "Cooperative Agreement Guidance for Public Health Emergency Preparedness," 2005, http://www.cdc.gov/phpr/documents/coopagreement-archive/fy2006/fy06announcement.pdf.

[42] M. Thorstensson, "Supporting observers in the field to perform model based data collection," in Proceedings of the 9th International ISCRAM Conference, Vancouver, Canada, April 2012.

[43] E. Savoia, M. A. Testa, P. D. Biddinger et al., "Assessing public health capabilities during emergency preparedness tabletop exercises: reliability and validity of a measurement tool," Public Health Reports, vol. 124, no. 1, pp. 138-148, 2009.

[44] M. Morin, "MIND-methods and tools for visualization of rescue operations," in Proceedings of the International Emergency Management Society's 8th Annual Conference (TIEMS '01), Oslo, Norway, June 2001.

[45] A. Johansson and M. Härenstam, "Knowledge communication: a key to successful crisis management," Biosecurity and Bioterrorism, vol. 11, supplement 1, pp. S260-S263, 2013.

[46] http://www.calhospitalprepare.org/post/what-difference-betweentabletop-exercise-drill-functional-exercise-and-full-scale-exercise.

[47] M. Crissey, M. Morin, and J. Jenvald, "Computer-supported emergency response training: observations from a field exercise," in Proceedings of the 12th International Training and Education Conference (ITEC '01), pp. 462-476, Lille, France, April 2001.

[48] D. J. Dausey, J. W. Buehler, and N. Lurie, "Designing and conducting tabletop exercises to assess public health preparedness for manmade and naturally occurring biological threats," $B M C$ Public Health, vol. 7, article 92, 2007.

[49] R. R. Kyle, D. K. Via, R. J. Lowy, J. M. Madsen, A. M. Marty, and P. D. Mongan, "A multidisciplinary approach to teach responses to weapons of mass destruction and terrorism using combined simulation modalities," Journal of Clinical Anesthesia, vol. 16, no. 2, pp. 152-158, 2004.

[50] R. Johnson and R. Johnson, "Anti-terrorism PTSD homeland security response scenarios using modelling and simulation," in Proceedings of the Homeland Security Modeling and Simulation (HLSMS '12), Part of the Autumn Simulation Multiconference (AutumnSim '12), vol. 44, no. 17 of Simulation Series, pp. 7-24, San Diego, Calif, USA, October 2012.

[51] D. Birkett and H. Mala-Jetmarova, "Terrorism and simulation of terrorist incidents across critical infrastructure," in Proceedings of the 19th International Congress on Modelling and Simulation-Sustaining Our Future: Understanding and Living with Uncertainty (MODSIM '11), Code 89164, pp. 3240-3245, Perth, Australia, December 2011.

[52] U. Satish and S. Streufert, "Training to defend: strategic management simulations," in Proceedings of the 1st International Workshop on Information Systems for Crisis Response and Management (ISCRAM '04), pp. 157-160, Brussels, Belgium, May 2004.

[53] COMSOL Multiphysics 5.1 User's Guide. 
[54] L. A. Poggi, A. Malizia, J. F. Ciparisse et al., "First experimental campaign to demonstrate STARDUST-upgrade facility diagnostics capability to investigate LOVA conditions," Journal of Fusion Energy, vol. 34, no. 6, pp. 1320-1330, 2015.

[55] A. Malizia, M. Gelfusa, G. Francia et al., "Design of a new experimental facility to reproduce LOVA and LOCA consequences on dust resuspension," Fusion Engineering and Design, vol. 9899, pp. 2191-2195, 2015.

[56] C. Bellecci, P. Gaudio, I. Lupelli et al., "STARDUST experimental campaign and numerical simulations: influence of obstacles and temperature on dust resuspension in a vacuum vessel under LOVA," Nuclear Fusion, vol. 51, no. 5, Article ID 053017, 2011.

[57] P. Gaudio, A. Malizia, and I. Lupelli, "Experimental and numerical analysis of dust resuspension for supporting chemical and radiological risk assessment in a nuclear fusion device," in Proceedings of the International Conference on Mathematical Models for Engineering Science (MMES '10), pp. 134-147, Puerto de la Cruz, Spain, November-December 2010.

[58] A. Malizia, M. Camplani, M. Gelfusa et al., "Dust tracking techniques applied to the STARDUST facility: first results," Fusion Engineering and Design, vol. 89, no. 9-10, pp. 2098-2102, 2014.

[59] P. Gaudio, A. Malizia, M. Camplani et al., "Shadowgraph technique applied to STARDUST facility for dust tracking: first results," Physics Procedia, vol. 62, pp. 97-101, 2015, 3rd International Conference Frontiers in Diagnostic Technologies, ICFDT3.

[60] C. Gordon, H.-W. Bartels, T. Honda et al., "An Overview of Results in the ITER Generic Site Safety Report (GSSR)," 2003, CT/P-17, http://www-pub.iaea.org/mtcd/publications/pdf/csp 019c/pdf/ctp_17.pdf. 


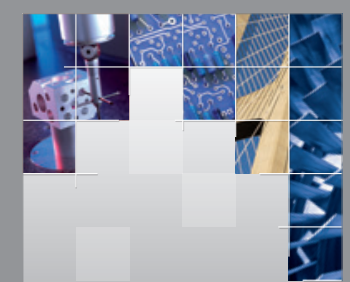

\section{Enfincering}
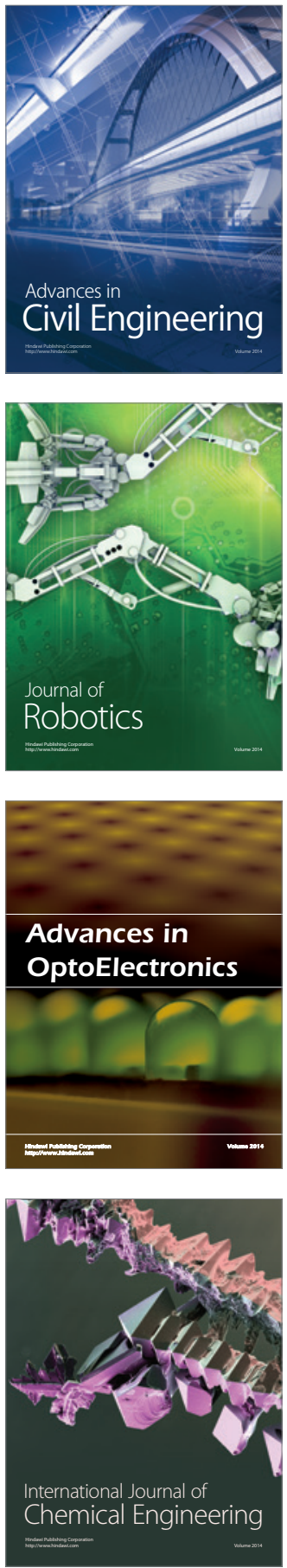

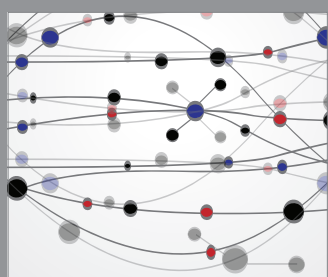

The Scientific World Journal

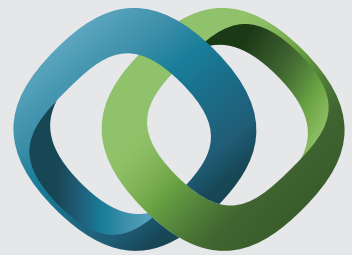

\section{Hindawi}

Submit your manuscripts at

http://www.hindawi.com
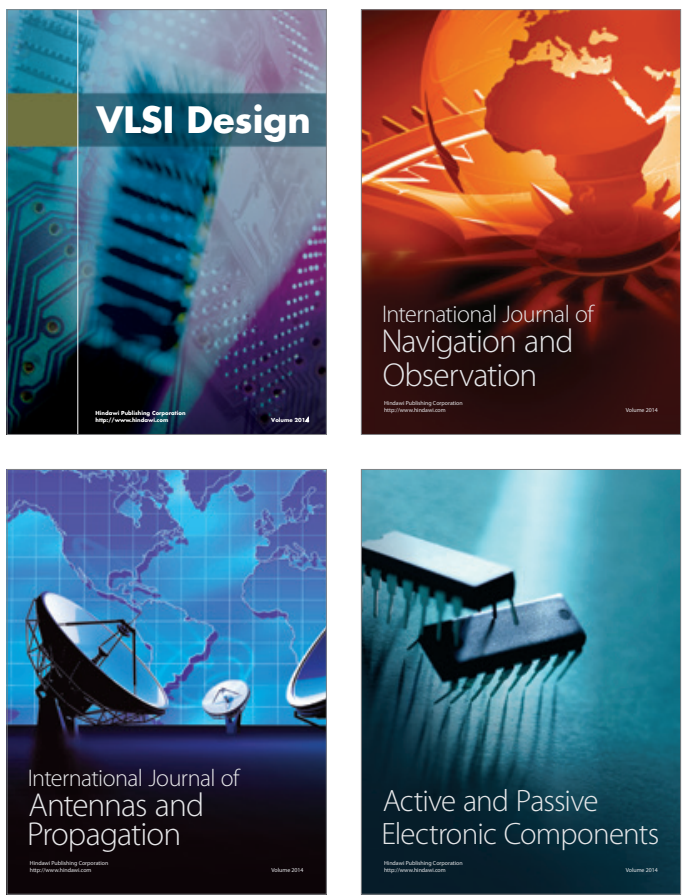
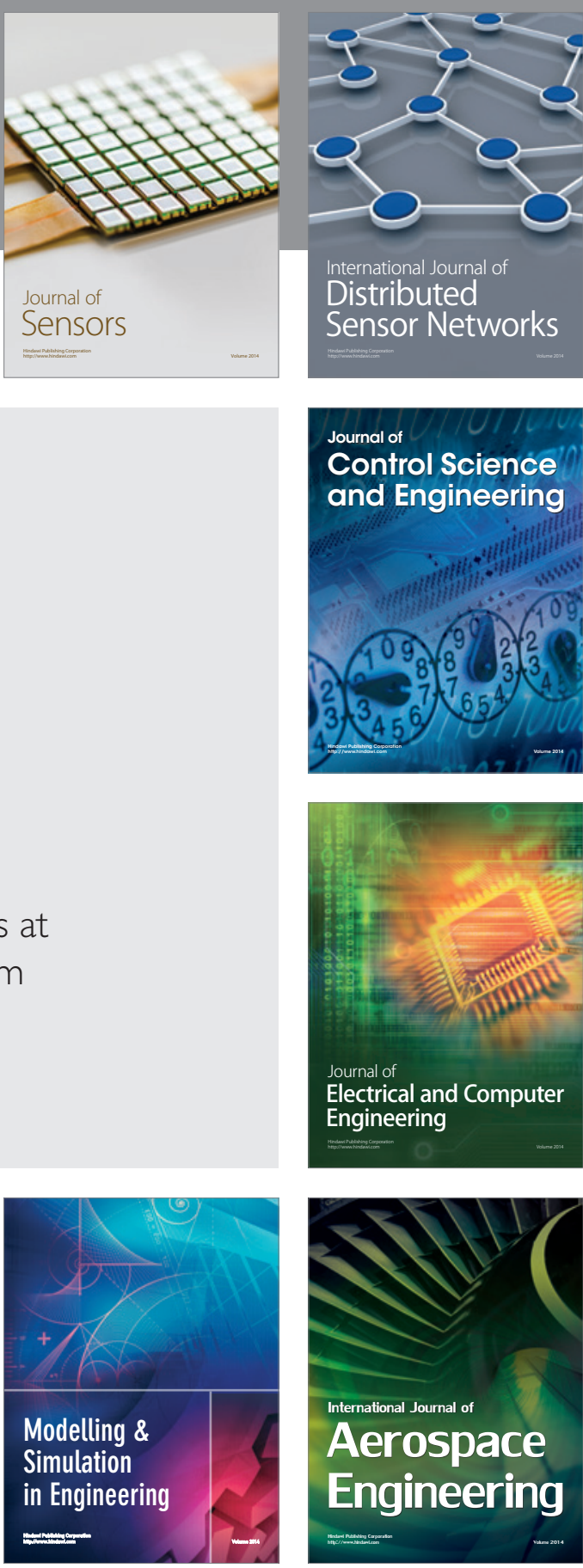

International Journal of

Distributed

Sensor Networks

Journal of

Control Science

and Engineering
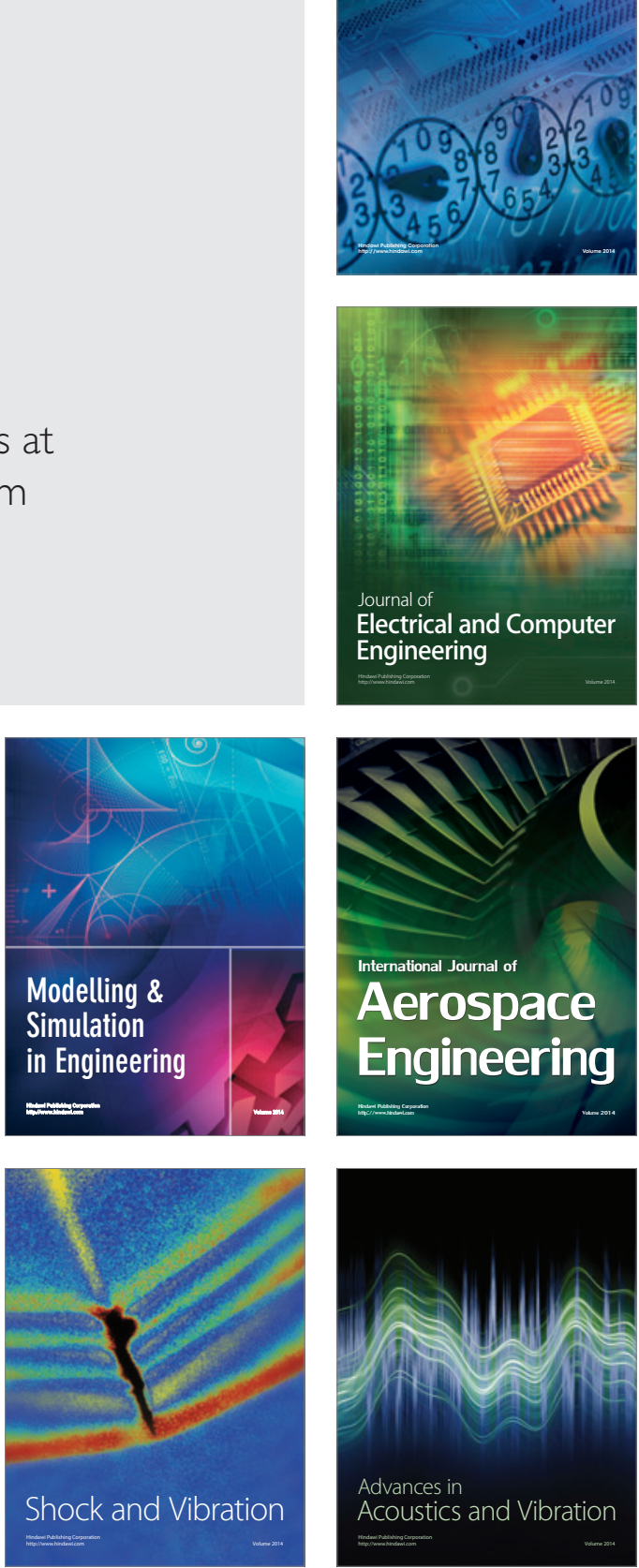